\title{
Clinical Study \\ Clinical Profile and Outcomes of Hair Dye Poisoning in a Teaching Hospital in Nellore
}

\author{
Raghu Kondle, ${ }^{1}$ Rama Mohan Pathapati, ${ }^{1,2}$ Satish Kumar Saginela, ${ }^{1}$ \\ Srinivas Malliboina, ${ }^{1}$ and Veera Prasad Makineedi ${ }^{1}$ \\ ${ }^{1}$ Narayana Medical College Hospital, Chinthareddypalem, Andhra Pradesh, Nellore 524002, India \\ ${ }^{2}$ Department Of Clinical Pharmacology, 27/2/1334, Nellore, Balaji-Nagar 524002, India
}

Correspondence should be addressed to Rama Mohan Pathapati, pill4ill@yahoo.co.in

Received 4 October 2011; Accepted 25 October 2011

Academic Editors: A. Banerjee, C. R. Harris, and Y. Kamijo

Copyright ( 2012 Raghu Kondle et al. This is an open access article distributed under the Creative Commons Attribution License, which permits unrestricted use, distribution, and reproduction in any medium, provided the original work is properly cited.

\begin{abstract}
Demographic profiles, volume consumed, time to hospitalization, clinical presentation, laboratory findings, treatment details, and outcomes of patients with hair dye poisoning were analyzed to assess the effect of Super Vasmol 33. The efficacy of methylprednisolone as compared to hydrocortisone in patients was also investigated. Findings show that there are significant differences in the clinical profiles laboratory markers such as markers of leukocytosis, rhabdomyolysis, and hepatitis among patients who consumed fewer volumes than larger volumes. Toxicity is dose dependent with increased morbidity and mortality. Consumption of even lower volumes resulted in hepatitis. For an apparently similar clinical and laboratory profile of patients, treatment with hydrocortisone is as effective as methylprednisolone in the clinical outcomes. These findings suggest that Super Vasmol 33 is emerging as a major source of poisoning.
\end{abstract}

\section{Introduction}

Poisoning is one of the preferred means of suicide. The most common poisoning encountered is ingestion of or exposure to insecticides and pesticides. Ingestion of Super-Vasmol33 , an emulsion-based hair dye, is in trend as a major source of suicidal poisoning following pesticides because of its easy availability and low cost. Accidental and intentional causes of poisoning have been reported from various parts of India [1-9]. It contains paraphenylenediamine (PPD) and a mixture of other chemicals that can damage the respiratory, muscular, renal, and hepatic systems and cause death [10]. The purpose of the study is to share our experience on clinical presentation, laboratory findings, and outcomes of hair dye poisoning in a rural part of Andhra Pradesh.

\section{Methods}

This retrospective study was conducted by the department of emergency medicine during the years from 2008 to 2011. Institutional Ethics Committee approved the study protocol for publishing the results. In these three years a total of 50 patients with hair dye poisoning were admitted to this hospital. Data extracted from the hospital records in specified forms. Demographic profile (age, gender, and socio economic status), volume consumed, time to hospitalization, clinical presentation, laboratory findings, treatment details and outcomes were analyzed. $25(50 \%)$ had vomiting prior to hospitalization. Three patients have received the primary care. On arrival, all patients received gastric lavage, antihistamines, parenteral steroids, and sodium bicarbonate. Hair dye is available in 50 and $100 \mathrm{~mL}$ bottles; total amount of contents minus volume remaining in the bottle gives a rough estimate of volume consumed. None of them were brought dead. Six patients left the hospital against medical advice, and they were contacted telephonically to know their health status. Serial liver function tests (LFTs) were available in 24 mechanically ventilated patients, and the times required for normalization of liver enzymes were analyzed. We explored the efficacy of methyl-prednisolone as compared to hydrocortisone in patients who consumed more than $50 \mathrm{~mL}$ of poison. 
Table 1: Clinical features and outcomes of Supervasmol-33 at admission.

\begin{tabular}{lcc}
\hline Clinical features at presentation & Number & Percentage \\
\hline Male/female & $9 / 41$ & $18 / 82$ \\
Cervicofacial edema & 44 & 88 \\
Difficulty in opening the mouth & 23 & 46 \\
Muscle weakness & 27 & 54 \\
Dark urine & 47 & 94 \\
Seizures & 2 & 4 \\
Acidosis & 30 & 60 \\
Hepatitis & 50 & 100 \\
Ventilator & 24 & 48 \\
ARF & 3 & 6 \\
Mortality & 2 & 4 \\
\hline
\end{tabular}

TABle 2: Demography, laboratory parameters, and outcomes at admission.

\begin{tabular}{lcc}
\hline Parameter & Mean \pm SD & Median and range \\
\hline Age $(\mathrm{yr})$ & $23.8 \pm 7.8$ & $22(15-60)$ \\
Volume consumed $(\mathrm{mL})$ & $75.2 \pm 38.4$ & $72.5(25-250)$ \\
Time to admission $(\mathrm{hrs})$ & $8.9 \pm 10.9$ & $6(1-72)$ \\
ICU stay (days) & $4.40 \pm 3.61$ & $3(1-14)$ \\
TLC $\left(1000\right.$ cells/mm $\left.{ }^{3}\right)$ & $15.7 \pm 5.56$ & $15(8-28)$ \\
CPK (U/Lin 1000) & $25.43 \pm 20.36$ & $22.5(1-68)$ \\
Serum creatinine $(\mathrm{mg} / \mathrm{dL})$ & $1.25 \pm 1.85$ & $0.9(0.3-13)$ \\
SGOT (U/L) & $1688.62 \pm 1407.32$ & $1192(118-4968)$ \\
SGPT (U/L) & $991.58 \pm 1084.36$ & $671(50-6155)$ \\
ALP (U/L) & $248.82 \pm 110.36$ & $239.5(98-685)$ \\
\hline
\end{tabular}

\section{Statistical Analysis}

The data incorprated in the case record forms were transferred to Microsoft excel spreadsheet 2007 (Microsoft Corp, Seattle, WA, USA). The statistical analysis was executed by Sigma graph pad prism software, USA Version-4, and SPSS version-11. Continuous data were presented as mean, median, range and standard deviation. Between groups, analysis was carried out by using " $t$-" test and ANOVA followed by the Bonferroni post hoc analysis. Categorical data were presented as actual numbers and percentages. Categorical variables were analysed with "Fischer's exact test." Pearson's and Spearman correlations were used to determine the association between volume consumed and the other variables. For statistical significance, the probability value of less than 0.05 was considered.

\section{Results}

The mean age and range of presentation was $23.8 \pm 7.8$ (1560) years, mean volume consumed $75.2 \pm 38.4$ (25-250) $\mathrm{mL}$, and mean time to hospitalization was $8.9 \pm 10.9$ (172) hrs. The classical features of hair dye poisoning such as cervicofacial edema with the hard protruding tongue was observed in $44(88 \%)$; out of these 22 had difficulty in opening their mouth. Dark urine was observed in 47 (94\%) and hepatitis in $50(100 \%)$ at presentation. None of the patients presented with ARF on admission. The clinical and laboratory features and outcomes were shown in Tables 1 and 2.

During the hospital stay, $30(60 \%)$ received hydrocortisone and $20(40 \%)$ methylprednisolone. 2 (4\%) needed an emergency tracheotomy during admission. During the hospital stay, $24(48 \%)$ required ventilatory support for airway compromise; among them, two (4\%) patients died due to respiratory failure during hospital stay. The mean ICU stay was $6.35 \pm 4.19$ days (1-14). The duration of ventilator support was $6.19 \pm 4.19$ days (1-13). In a group of 18 patients with ventilator support, time to normalization of liver enzymes was found to be $8.75 \pm 1.98$ days. Three patients $(6 \%)$ developed ARF after 72 hours of poisoning and recovered with hemodialysis.

It can be noticed from Table 3 that the proportion of patients who had cervicofacial edema was apparently similar in both groups. All patients who ingested more than $50 \mathrm{~mL}$ of poison had difficulty in mouth opening, and 23 patients out of this group required ventilator support suggesting the severity of cervicofacial edema with larger volumes. There are significant differences in the clinical profiles laboratory markers such as markers of leucocytosis (TLC), rhabdomyolysis (CPK), and hepatitis (SGOT, SGPT and ALP) between patients who consumed fewer volumes and those who consumed larger volumes. The length of ICU stay was significantly more in patients who consumed more volume $(6.19 \pm 4.19$ days versus $2.42 \pm 0.96$ days, $P<0.0001)$.

We evaluated the effect of time to hospitalization (from Table 4), on the clinical and laboratory profile and found that the classical features of poisoning such as cervicofacial edema, dark-coloured urine, and hepatitis appear as early as in six hours. However, the development of full-blown picture of poisoning occurs between 6 and $12 \mathrm{hrs}$ after this was substantiated by statistically higher values of total leukocyte count, CPK, SGOT, and SGPT in patients who presented between 6 and 12 hrs. However, the values of these markers were not elevated as compared to patients who presented after more than $12 \mathrm{hrs}$ of ingestion.

We explored the efficacy of methylprednisolone versus hydrocortisone in patients who consumed more than $50 \mathrm{~mL}$ of poison, and the results are shown in Table 5. In comparison, age, volume consumed, time of admission, clinical and laboratory profiles at admission were similar in both groups, and there were no statistically significant differences in the length of hospital stay, ventilator support and clinical outcomes between the two groups.

It can be seen from Table 6 that patients requiring dialysis correlate well with time to hospitalization, $(r=0.44, P=$ $0.002)$, CPK $(r=0.34, P=0.02)$, and SGOT $(r=0.41$, $P=0.004)$. It is possible that these patients might have received primary care elsewhere and referred to this hospital once renal failure has set in. It is also appreciable that these patients had statistically significant levels in CPK and SGOT than the no-dialysis group. Time to hospitalization (hrs) has been shown to be significant predictor of dialysis than patients who does not require dialysis $(29.0 \pm 37.2$ versus 7.7 $\pm 6.2 \mathrm{hrs}, P=0.001$ ), respectively (Figure 1 ). 
TABLE 3: Clinical features and outcomes based on volume consumed.

\begin{tabular}{lccc}
\hline Volume & $\begin{array}{c}<0 \mathrm{~mL} \\
(N=23)\end{array}$ & $\begin{array}{c}\geq 50 \mathrm{~mL} \\
(N=27)\end{array}$ & $P$-Value \\
\hline Male/female & $6 / 17$ & $3 / 24$ & 0.27 \\
Age (Yrs) & $23.96 \pm 6.52$ & $23.67 \pm 9.00$ & 0.89 \\
Volume ingested (mL) & $46.74 \pm 15.12$ & $99.44 \pm 35.50$ & 0.33 \\
Time to admission (Hr) & $7.30 \pm 7.75$ & $10.33 \pm 13.02$ & 0.00 \\
ICU stay (Days) & $2.42 \pm 0.96$ & $6.19 \pm 4.19$ & 0.00 \\
Duration of ventilator support (days) & $1.42 \pm 0.96$ & $5.78 \pm 4.23$ & 0.00 \\
TLC (1000 cells/mm3) & $11.86 \pm 2.62$ & $18.96 \pm 5.33$ & 0.00 \\
CPK (U/Lin 1000) & $11.13 \pm 10.11$ & $37.63 \pm 18.84$ & 0.10 \\
Serum creatinine (mg/dL) & $0.78 \pm 0.19$ & $1.65 \pm 2.46$ & 0.00 \\
SGOT (U/L) & $757.00 \pm 526.54$ & $2482.22 \pm 1440.89$ & 0.00 \\
SGPT (U/L) & $515.43 \pm 380.92$ & $1397.19 \pm 1312.18$ & 0.01 \\
ALP (U/L) & $203.83 \pm 89.24$ & $287.15 \pm 113.56$ & 1.0 \\
Cervicofacial edema & 20 & 24 & 0.000 \\
Difficulty in mouth opening & 0 & 22 & 0.000 \\
Muscle weakness & 4 & 23 & 0.49 \\
Seizures & 0 & 2 & 0.000 \\
Acidosis & 6 & 23 & 0.000 \\
Ventilator & 1 & 2 & 0.24 \\
ARF & 0 & 0 & 0.49 \\
Mortality & & 23 &
\end{tabular}

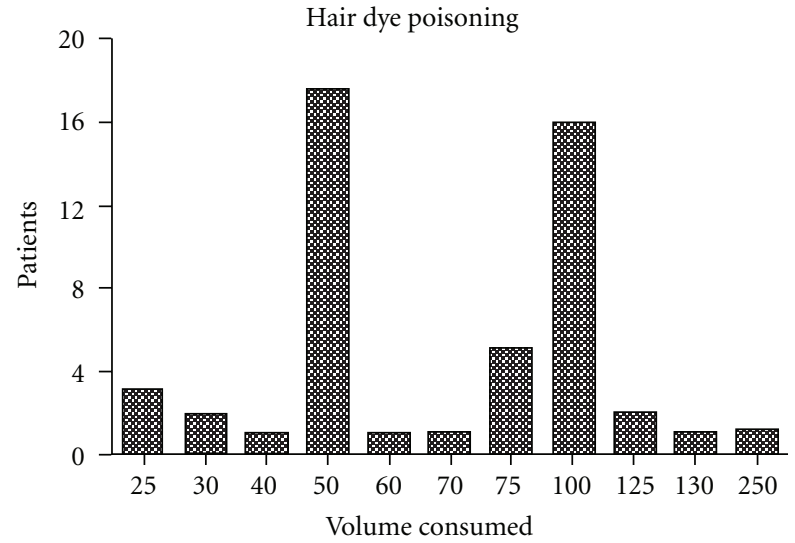

FIgURE 1: Frequency distribution of hair dye consumption.

\section{Discussion}

Supervasmol-33 is emerging as a poison in this area. The constituents of this hair dye include PPD (4\%), resorcinol, propylene glycol, ethylenediaminetetraacetic acid (EDTA), sodium, liquid paraffin, cetostearyl alcohol, sodium lauryl sulphate, herbal extracts, preservatives, and perfumes [10]. Some of these ingredients are known toxins with multiorgan effects, while the toxicity profiles of others are not known. The combined effect of the individual compounds may be responsible for its significant morbidity and mortality.
Accidental or intentional poisoning results in systemic toxicity [11] in a dose-dependent manner [12]. In our study, we observed the classical features of poisoning within four to six hours of ingestion. We also found that that the markers of leucocytosis, rhabdomyolysis, and hepatitis were significantly higher in patients who consumed larger volumes suggesting dose-dependant toxicity.

We analyzed the demography and laboratory profiles of patients who required dialysis and found that patients requiring dialysis correlate well with time to hospitalization, $\mathrm{CPK}$, and SGOT. However, the onset of renal failure was delayed as much as days.

In this study, self-poisoning tendency was predominant in young females of lower and middle socioeconomic class. It is usually ingested to threaten the family members if their demands were not met. The features of poisoning were observed with consumption of even lower volumes such as $25 \mathrm{~mL}$. There was a threefold increase in the values of the markers of rhabdomyolysis and hepatitis upon consumption of larger volume suggesting its dose-dependent toxicity. With large volumes, there was an increase in morbidity such as patients needing ventilator support, duration of hospital stay and mortality.

The classical features of acute poisoning were seen within six hrs; untreated patients developed full-blown picture of poisoning between 6 and $12 \mathrm{hrs}$, and this was substantiated by significantly higher values of total leucocyte count, CPK, SGOT, and SGPT in patients who presented between 6$12 \mathrm{hrs}$ than those who presented under $6 \mathrm{hrs}$. In patients who 
TABLE 4: Clinical features and outcomes based on time to admission.

\begin{tabular}{|c|c|c|c|c|}
\hline Time to hospitalization & $\begin{array}{l}<6 \text { hours } \\
(N=24)\end{array}$ & $\begin{array}{l}6-12 \text { hours } \\
(N=17)\end{array}$ & $\begin{array}{l}>12 \text { hours } \\
(N=9)\end{array}$ & $P$ value \\
\hline Age (years) & $24.38 \pm 5.76$ & $23.35 \pm 9.98$ & $23.11 \pm 9.16$ & $\begin{array}{l}1 \text { versus } 2=1.00 \\
1 \text { versus } 3=1.00 \\
2 \text { versus } 3=1.00\end{array}$ \\
\hline Volume consumed (mL) & $61.04 \pm 26.78$ & $87.06 \pm 25.68$ & $90.56 \pm 67.01$ & $\begin{array}{l}1 \text { versus } 2=0.89 \\
1 \text { versus } 3=0.13 \\
2 \text { versus } 3=1.00\end{array}$ \\
\hline ICU stay (Days) & $3.70 \pm 3.36$ & $6.08 \pm 3.93$ & $3.29 \pm 3.04$ & $\begin{array}{l}1 \text { versus } 2=0.19 \\
1 \text { versus } 3=1.00 \\
2 \text { versus } 3=0.29\end{array}$ \\
\hline TLC $(1000$ cells/mm³ $)$ & $13.92 \pm 5.11$ & $17.29 \pm 5.98$ & $17.56 \pm 4.85$ & $\begin{array}{l}1 \text { versus } 2=0.16 \\
1 \text { versus } 3=0.26 \\
2 \text { versus } 3=1.00\end{array}$ \\
\hline CPK (U/Lin 1000) & $15.92 \pm 14.31$ & $34.82 \pm 17.83$ & $33.11 \pm 27.83$ & $\begin{array}{l}1 \text { versus } 2=0.00 \\
1 \text { versus } 3=0.07 \\
2 \text { versus } 3=1.00\end{array}$ \\
\hline Serum creatinine (mg/dL) & $1.33 \pm 2.49$ & $1.06 \pm 0.82$ & $1.38 \pm 1.30$ & $\begin{array}{l}1 \text { versus } 2=1.00 \\
1 \text { versus } 3=1.00 \\
2 \text { versus } 3=1.00\end{array}$ \\
\hline SGOT (U/L) & $942.54 \pm 843.79$ & $2710.12 \pm 1554.68$ & $1748.67 \pm 1165.54$ & $\begin{array}{l}1 \text { versus } 2=0.00 \\
1 \text { versus } 3=0.26 \\
2 \text { versus } 3=0.16\end{array}$ \\
\hline SGPT (U/L) & $625.75 \pm 565.31$ & $1527.76 \pm 1511.39$ & $954.33 \pm 837.01$ & $\begin{array}{l}1 \text { versus } 2=0.02 \\
1 \text { versus } 3=1.00 \\
2 \text { versus } 3=0.55\end{array}$ \\
\hline $\operatorname{ALP}(\mathrm{U} / \mathrm{L})$ & $231.00 \pm 130.37$ & $250.76 \pm 61.98$ & $292.67 \pm 122.16$ & $\begin{array}{l}1 \text { versus } 2=1.00 \\
1 \text { versus } 3=0.48 \\
2 \text { versus } 3=1.00\end{array}$ \\
\hline Male/female & $6 / 18$ & $1 / 16$ & $2 / 7$ & 0.27 \\
\hline Dark Urine & 21 & 17 & 9 & 0.17 \\
\hline Cervicofacial edema & 19 & 17 & 8 & 0.12 \\
\hline Ventilator & 9 & 11 & 4 & 0.22 \\
\hline ARF & 0 & 0 & 3 & 0.24 \\
\hline Mortality & 1 & 0 & 1 & 0.33 \\
\hline
\end{tabular}

were admitted into the hospital more than $12 \mathrm{hrs}$ of ingestion these markers were not statistically different as compared to those between 6-12 hrs.

Poisoning due to PPD has a high mortality. Therefore, early recognition can be life saving. As there is no specific antidote, the management of poisoning includes gastric lavage, antihistamines, parenteral steroids, and alkalinization of the urine. Respiratory distress is the major early challenge, which may require ventilator support. Renal support in the form of dialysis is required in acute renal failure. Limited data were available on the head to head comparison of hydrocortisone and methyl prednisolone in hair dye poisoning. In this study, we compared the efficacy of hydrocortisone and methyl prednisolone and found that, in an apparently similar clinical and laboratory profile of patients who consumed more than $50 \mathrm{~mL}$ of poison, treatment with hydrocortisone is as effective as methylprednisolone in the clinical outcomes like duration on ventilator support. However, caution has to be executed in interpretation of this study results because of small sample size.

\section{Study Limitations}

Serial measurements of laboratory parameters were not available to assess the time to normalization of all lab parameters. Assessment of effect of individual variables on clinical outcomes needs much larger sample size.

\section{Conclusion}

This could be a warning to the Asian countries that supervasmol-33 is an emerging alternative to organophosphorus poisoning because of its easy availability and low cost. Toxicity is dose dependant with increased morbidity and mortality. However, consumption of even lower volumes as few as $25 \mathrm{~mL}$ resulted in hepatitis. We recommend introducing less 
TABLE 5: Clinical features and outcomes based on type of corticosteroid.

\begin{tabular}{lccc}
\hline Patients who consumed more than & $\begin{array}{c}\text { Methyl prednisolone } \\
(n=14)\end{array}$ & $\begin{array}{c}\text { Hydrocortisone } \\
(n=13)\end{array}$ & $P$ value \\
\hline Age $(\mathrm{Yr})$ & $24.21 \pm 11.38$ & $23.08 \pm 5.88$ & $91.15 \pm 18.84$ \\
Volume consumed (mL) & $107.14 \pm 45.39$ & $12.08 \pm 18.26$ & 0.75 \\
Time to admission (Hrs) & $8.71 \pm 5.04$ & $2 / 11$ & 0.24 \\
Male/female & $1 / 13$ & $19.93 \pm 5.32$ & 0.51 \\
TLC in thousands (Cells/mm $\left.{ }^{3}\right)$ & $18.07 \pm 5.39$ & $43.14 \pm 15.45$ \\
CPK in thousands (U/mL) & $32.66 \pm 20.85$ & $1.27 \pm 1.07$ \\
SC (mg/dL) & $2.01 \pm 3.29$ & $2836.69 \pm 1251.35$ \\
SGOT (IU/dL) & $2153.07 \pm 1569.89$ & $1260.62 \pm 1111.04$ \\
SGPT (IU/dL) & $1524 \pm 1506.06$ & $292.23 \pm 141.52$ \\
ALP (IU/dL) & $282.43 \pm 85.19$ & 11 & 0.37 \\
Ventilator & 12 & 2 & 0.15 \\
ARF & 1 & 1 & 0.44 \\
Mortality & 1 & $6.56 \pm 5.15$ \\
ICU stay (Days) & $5.92 \pm 3.53$ & $3.96 \pm 4.37$ \\
Duration on ventilator support (days) & $4.00 \pm 3.37$ & $8.73 \pm 2.28$ \\
Normalization of LFT (Days) & $8.92 \pm 1.78$ & 0.61 \\
\hline
\end{tabular}

TABLE 6: Clinical features and outcomes of on dialysis.

\begin{tabular}{lccc}
\hline & $\begin{array}{c}\text { No dialysis } \\
(n=47)\end{array}$ & $\begin{array}{c}\text { dialysis } \\
(n=3)\end{array}$ & $P$ value \\
\hline Age (years) & $23.5 \pm 7.7$ & $28.3 \pm 10.4$ & 0.31 \\
Volume (mL) & $73.6 \pm 39.1$ & $100.0 \pm 0.0$ & 0.25 \\
$\begin{array}{l}\text { Time to } \\
\text { hospitalization (hrs) }\end{array}$ & $7.7 \pm 6.2$ & $29.0 \pm 37.2$ & 0.001 \\
CPK in thousands & $23.8 \pm 19.7$ & $51.7 \pm 9.1$ & 0.02 \\
(U/mL) & & & \\
SGOT (IU/dL) & $1545.4 \pm 1298.9$ & $3931.7 \pm 1300.5$ & 0.003 \\
SGPT (IU/dL) & $998.1 \pm 1109.4$ & $889.7 \pm 696.5$ & 0.87 \\
ALP (IU/dL) & $249.6 \pm 112.4$ & $236.7 \pm 86.0$ & 0.85 \\
ICU stay (Days) & $4.2 \pm 3.5$ & $6.7 \pm 5.0$ & 0.26 \\
\hline
\end{tabular}

than $25 \mathrm{~mL}$ sachets in place of the currently available $50 \mathrm{~mL}$ and $100 \mathrm{~mL}$ since such small volumes can reduce the severity of poisoning though it is difficult to put a stop to determined suicides.

\section{Disclosure}

None of the authors have received any financial benefit from any source while conducting this study.

\section{References}

[1] A. Chrispal, A. Begum, I. Ramya, and A. Zachariah, "Hair dye poisoning-an emerging problem in the tropics: an experience from a tertiary care hospital in South India," Tropical Doctor, vol. 40, no. 2, pp. 100-103, 2010.

[2] M. Sahay, R. Vani, and S. Vali, "Hair dye ingestion-an uncommon cause of acute kidney injury," Journal of Association of Physicians of India, vol. 57, no. 11, pp. 743-744, 2009.
[3] K. Sampathkumar and S. Yesudas, "Hair dye poisoning and the developing world," Journal of Emergencies, Trauma and Shock, vol. 2, no. 2, pp. 129-131, 2009.

[4] P. Bhargava and P. Matthew, "Hair dye poisoning," Journal of Association of Physicians of India, vol. 55, pp. 871-872, 2007.

[5] S. Anuradha, S. Arora, S. Mehrotra, A. Arora, and P. Kar, "Acute renal failure following para-phenylenediamine (PPD) poisoning: a case report and review," Renal Failure, vol. 26, no. 3, pp. 329-332, 2004.

[6] V. Midha, N. S. Khaira, G. Awasthi, H. S. Pannu, A. Sood, and S. Malhotra, "Hair dye poisoning-a case," Renal Failure, vol. 22, no. 1, pp. 109-111, 2000.

[7] S. S. Soni, A. Nagarik, M. Dinaker, G. Adikey, and A. Raman, "Systemic toxicity of paraphenylenediamine," Indian Journal of Medical Sciences, vol. 63, no. 4, pp. 164-166, 2009.

[8] P. K. Jain, N. Agarwal, A. K. Sharma, and A. Akhtar, "Prospective study of ingestional hair dye poisoning in Northern India," Journal of Clinical Medicine Research, vol. 3, no. 1, pp. 9-19, 2011.

[9] S. Singla, S. Miglani, A. K. Lal, P. Gupta, and A. K. Agarwal, "Para-phenylenediamine (PPD) poisoning," Journal of the Indian Academy of Clinical Medicine, vol. 6, no. 3, pp. 236-238, 2005.

[10] G. J. Nohynek, R. Fautz, F. Benech-Kieffer, and H. Toutain, "Toxicity and human health risk of hair dyes," Food and Chemical Toxicology, vol. 42, no. 4, pp. 517-543, 2004.

[11] M. Abdelraheem, E. T. Ali, R. Hussien, and E. Zijlstra, "Paraphenylene diamine hair dye poisoning in an adolescent," Toxicol Ind Health, vol. 27, no. 10, pp. 911-913, 2011.

[12] F. Q. Hou, X. H. Lin, Y. Y. Yu, T. L. Wang, and G. Q. Wang, "Severe liver injury induced by repeated use of hair dye," Chinese Medical Journal, vol. 122, no. 7, pp. 875-877, 2009. 


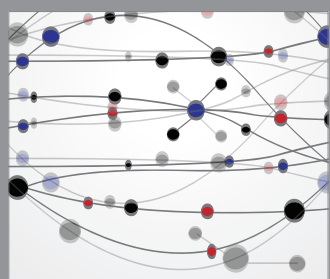

The Scientific World Journal
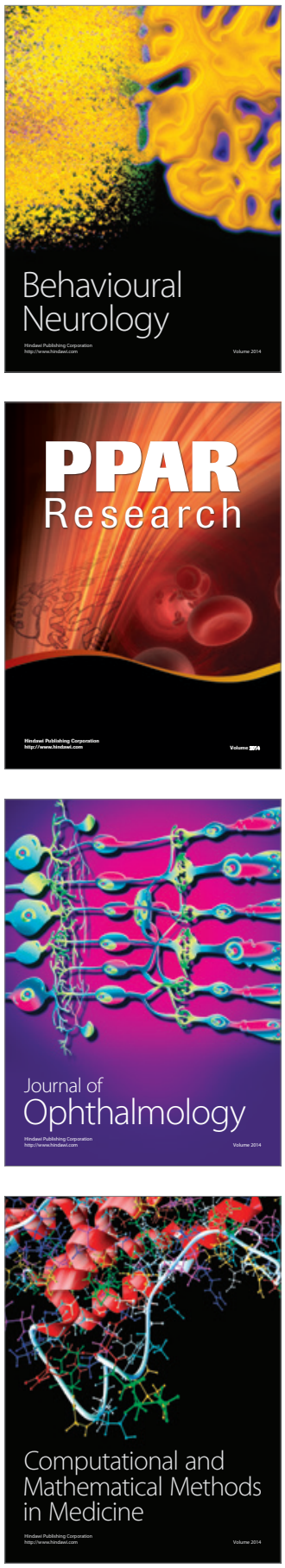

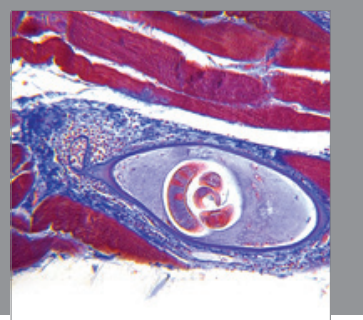

Gastroenterology

Research and Practice
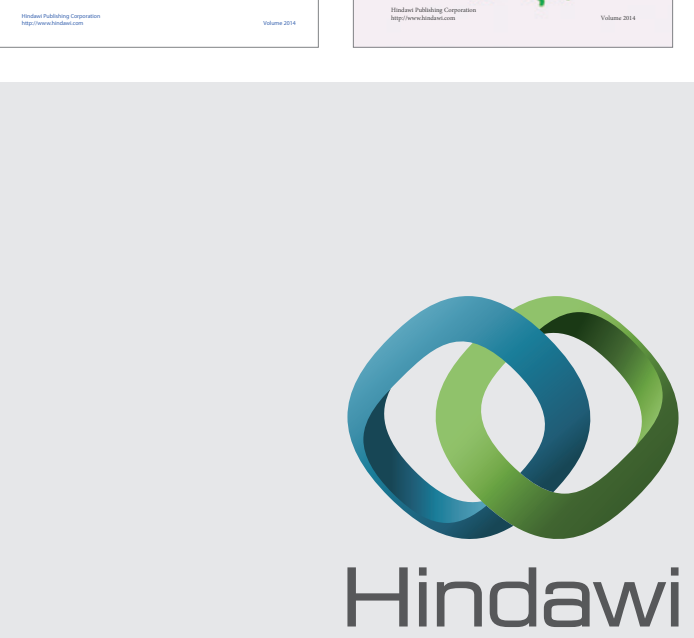

Submit your manuscripts at

http://www.hindawi.com
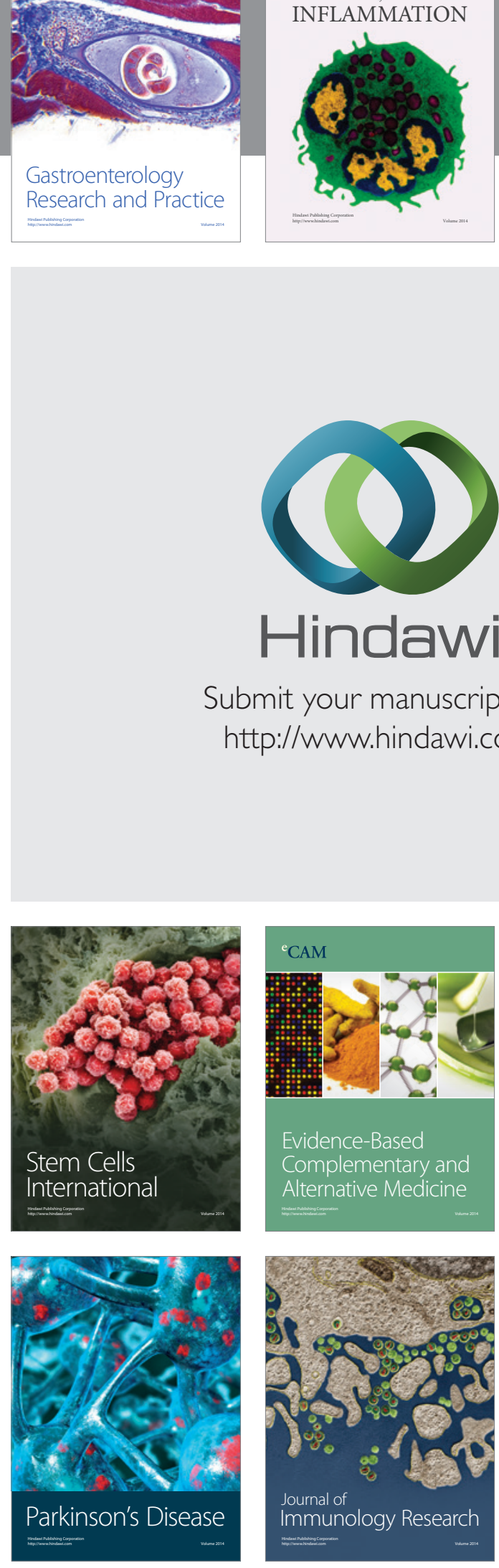

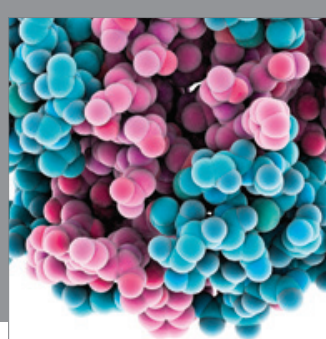

Diabetes Research
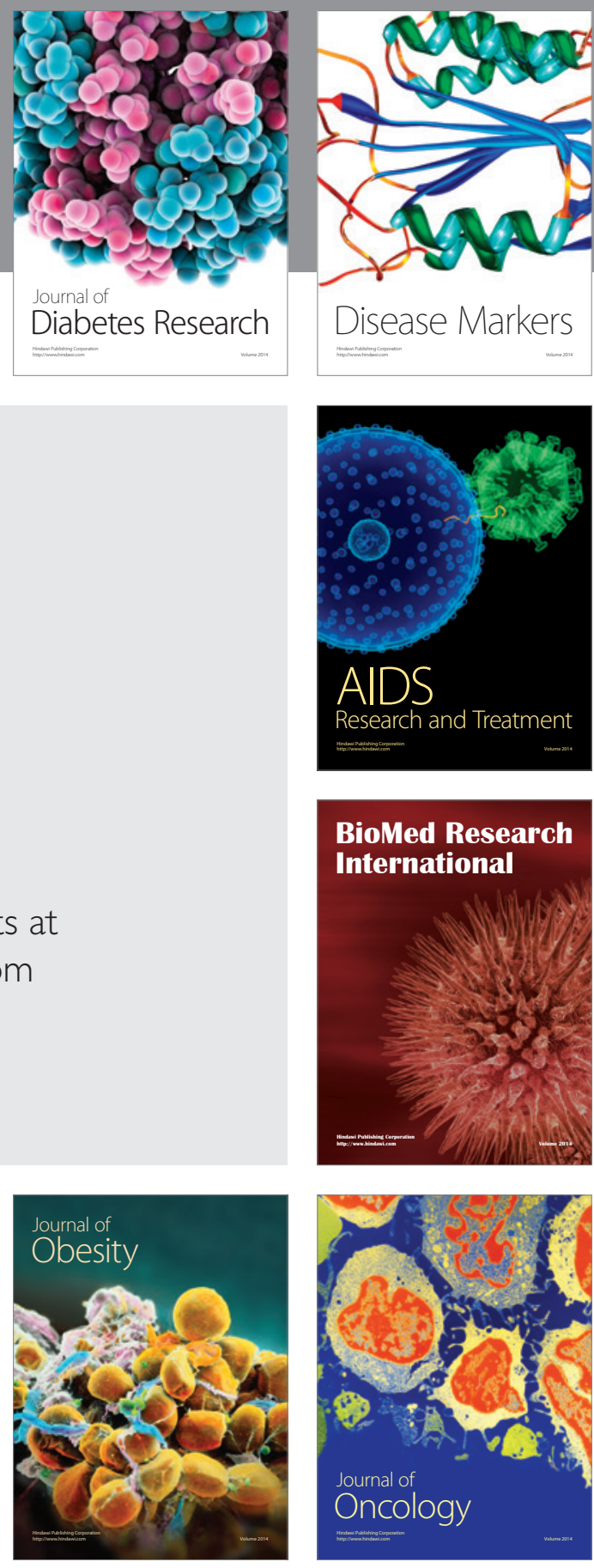

Disease Markers

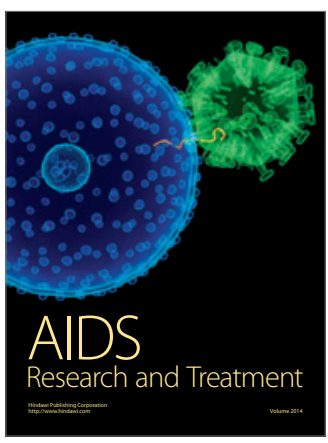

BioMed Research

International
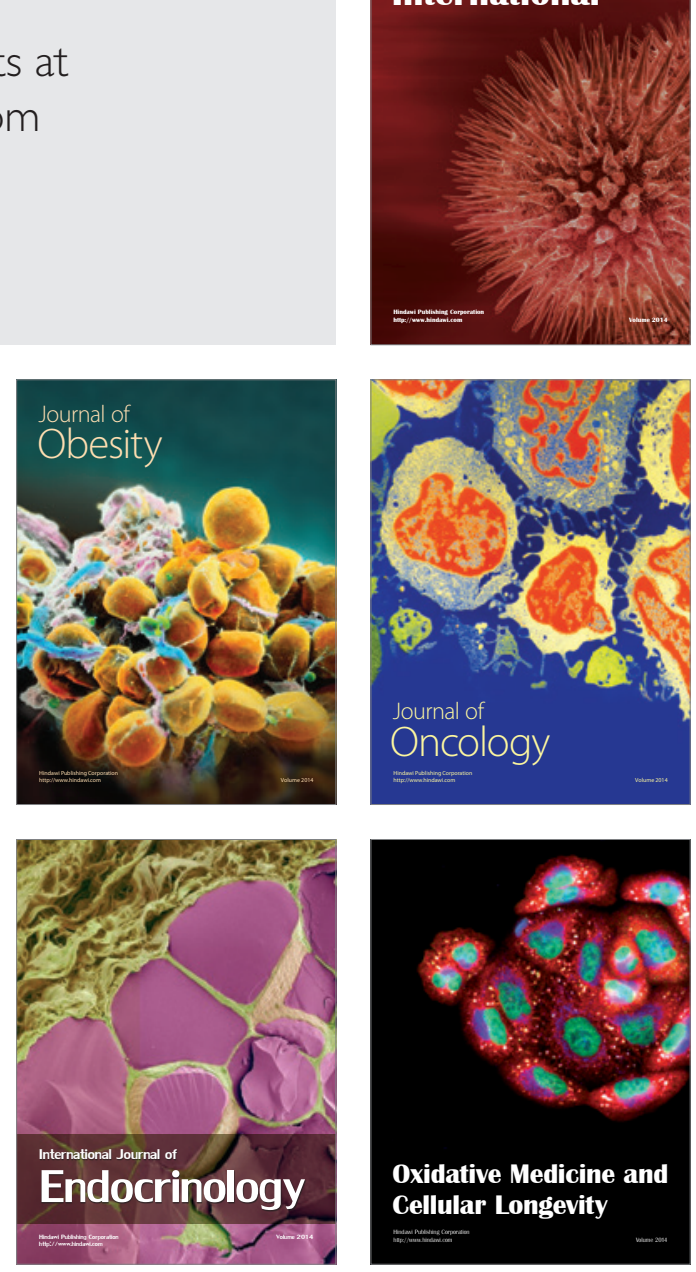